\title{
EXEQUATUR DE SENTENCIA EXTRANJERA RELATIVA A GESTACIÓN POR SUSTITUCIÓN: COMENTARIO AL AUTO DE LA AUDIENCIA PROVINCIAL DE BARCELONA (SECCIÓN 12a-CIVIL), DE 18 DE DICIEMBRE DE 2019
}

\author{
EXEQUATUR PROCEDURE OF FOREIGN JUDGEMENT ABOUT \\ SURROGACY: COMMENTS ON THE JUDICIAL DECREE \\ OF THE BARCELONA PROVINCIAL COURT \\ (12 ${ }^{\mathrm{TH}}$ SECTION-CIVIL), ISSUED ON DECEMBER 18, 2019
}

\author{
Dra. Silvia Vilar González* \\ Profesora Universitat Jaume I (Castellón de la Plana) \\ Profesora Universidad Internacional de La Rioja \\ Oficial de Notaría
}

Recibido: 02.05.2020 / Aceptado: 26.05.2020

DOI: https://doi.org/10.20318/cdt.2020.5668

\begin{abstract}
Resumen: Este trabajo analiza un Auto de la Audiencia Provincial de Barcelona, de 18 de diciembre de 2019, por el que se estima el recurso de apelación interpuesto contra la inadmisión a trámite in limine litis de una demanda de solicitud de reconocimiento de una resolución extranjera. Dicha inadmisión se sustentaba en el hecho de que, al tener que ver la resolución extranjera con un proceso de gestación por sustitución, la misma fue considerada contraria al orden público español y, por lo tanto, desestimada la demanda. Sin embargo, conforme ha indicado el Tribunal Supremo en reiteradas ocasiones, tan solo cabe inadmitir a trámite una demanda en los casos y por las causas legalmente previstas, correspondiendo a los órganos jurisdiccionales garantizar el derecho fundamental a la tutela judicial efectiva.
\end{abstract}

Palabras clave: gestación por sustitución, exequátur, inadmisión in limine litis, orden público internacional, derecho a la tutela judicial efectiva.

\begin{abstract}
This paper examines a Judicial Decree of the Barcelona Provincial Court, issued on December 18, 2019, which allows the appeal against the non-admission in limine litis of an application for recognition of a foreign decision. The non-admission was based on the fact that, since the foreign decision was related to a surrogacy process, it was considered contrary to Spanish public policy and was therefore rejected. Nevertheless, as the Spanish Supreme Court has indicated on several occasions, claims may only be rejected in the cases and for the reasons provided for by law, and it is up to the Courts to guarantee the fundamental right to effective judicial protection.
\end{abstract}

Keywords: surrogacy, exequatur procedure, non-admission in limine litis, international public policy, the fundamental right to effective judicial protection.

Sumario: I. Introducción. II. Antecedentes de hecho que dan lugar al recurso planteado. III. Fundamentos jurídicos apreciados por la Audiencia Provincial de Barcelona. IV. Parte dispositiva. V. Consideraciones finales.

"Miembro del Grupo de Investigación "Centro de Estudios de Derecho y Relaciones Internacionales (CEDRI)". 


\section{Introducción}

1. El artículo 10 de la Ley española 14/2006, de 26 de mayo, sobre técnicas de reproducción humana asistida (en lo sucesivo, LTRHA) establece la nulidad de pleno derecho de los contratos por los que "se convenga la gestación, con o sin precio, a cargo de una mujer que renuncia a la filiación materna a favor del contratante o de un tercero". Ello no impide que dicha práctica sí sea legal en muchos otros países, como en Grecia, Reino Unido, Portugal, República Sudafricana o Ucrania, así como en determinados Estados de EEUU, como pueden ser Arkansas, California o Illinois, lugares a los que muchas familias españolas acuden, cada vez más, con la finalidad de convertir en realidad su deseo de formar una familia.

2. Cuando estas personas logran regresar a España acompañadas de sus hijos recién nacidos en el extranjero, en algunas ocasiones consiguen, sin el mayor problema -pero no sin menos incertidumbre-, alcanzar la inscripción de su nacimiento y filiación en el Registro Civil correspondiente a través de los distintos cauces legales que ha ido habilitando en los últimos años la anterior Dirección General de los Registros y del Notariado ${ }^{2}$. Pero, en muchas otras ocasiones, se ven abocadas al tortuoso laberinto judicial que se deriva de la insuficiente regulación española en esta materia, quedando expuestas a una clara situación de falta de previsibilidad y de inseguridad jurídica.

3. Pues bien, en esta última tesitura se encontró el recurrente en apelación del Auto que nos ocupa, "D. Juan Luis"3, al solicitar el exequátur de una resolución judicial extranjera que tiene que ver con un "contrato de gestación", tal y como veremos seguidamente.

\section{Antecedentes de Hecho que dan lugar al recurso planteado}

4. El recurso de apelación que motivó el presente pronunciamiento, se interpuso contra un Auto de 26 de junio de 2019 dictado por el Juzgado de Primera Instancia e Instrucción número 2 de los de Santa Coloma de Gramenet (Barcelona), por el que se inadmitió a trámite una demanda en la que se solicitaba el reconocimiento de una resolución extranjera (procedimiento de origen: exequátur 410/2018). El referido Juzgado de Primera Instancia gozaba de competencia para conocer de este asunto en materia civil, en base a lo dispuesto en el artículo 85.5 de la Ley Orgánica del Poder Judicial, que atribuye a estos órganos facultades para conocer de las "solicitudes de reconocimiento y ejecución de sentencias y otras resoluciones judiciales extranjeras y de la ejecución de laudos o resoluciones arbitrales extranjeros, a no ser que, con arreglo a lo acordado en los tratados y otras normas internacionales, corresponda su conocimiento a otro Juzgado o Tribunal"s.

5. De los Antecedentes de Hecho reflejados en el Auto de la Audiencia Provincial no se desprende ninguna información sobre el contenido de la resolución extranjera objeto de la solicitud de reconocimiento, por lo que resulta necesario continuar avanzando hasta el Fundamento de Derecho segundo para poder determinar que la misma está relacionada con un contrato de gestación subrogada, tal y como hemos señalado con anterioridad. No obstante, no resulta posible precisar si el petitum formulado en sede jurisdiccional tiene que ver con el reconocimiento del nacimiento y filiación de un menor nacido a partir de esta técnica en el extranjero -lo más probable- o, por ejemplo, con la solicitud de ejecución de una sentencia extranjera condenatoria al pago de alguna cantidad derivada de un contrato de gestación subrogada.

\footnotetext{
${ }^{1}$ Art. 10.1 Ley 14/2006, de 26 de mayo, sobre técnicas de reproducción humana asistida.

2 Actualmente, Dirección General de Seguridad Jurídica y Fe Pública, tras la aprobación del Real Decreto 139/2020, de 28 de enero, por el que se establece la estructura orgánica básica de los departamentos ministeriales.

${ }^{3}$ AntecedentedeHechoPrimerodelAAPBarcelona478/2019(sección 12a), de 18diciembre2019[ECLI:ES:APB:2019:10320A] (en lo sucesivo, AAP Barcelona 18 diciembre 2019).

${ }^{4}$ Párrafo $6^{\circ}$ Fundamento de Derecho Segundo AAP Barcelona 18 diciembre 2019.

${ }^{5}$ Art. 85.5 Ley Orgánica 6/1985, de 1 de julio, del Poder Judicial.
} 
6. Tampoco resulta posible identificar, ni tan siquiera, el país del que procede la referida sentencia judicial extranjera cuyo reconocimiento y ejecución se pretende, lo que hubiese aportado más luz al asunto.

7. Lo que sí resulta evidente, también a partir de la lectura de los Fundamentos de Derecho, es que el Juzgado de Primera Instancia de referencia, sustentó la inadmisión a trámite de la demanda en el artículo 46 de la Ley 29/2015, de 30 de julio, de Cooperación Jurídica Internacional en Materia Civil (LCJIMC), que contempla la posibilidad de denegar el reconocimiento de una resolución judicial extranjera firme basándose en el hecho de que la misma resulte contraria al orden público ${ }^{6}$, así como en la nulidad que se desprende del mencionado artículo 10 LTRHA.

\section{Fundamentos jurídicos apreciados por la Audiencia Provincial de Barcelona}

8. Los magistrados de la Audiencia Provincial de Barcelona comenzaron fundamentando jurídicamente su decisión partiendo del apartado primero del artículo 403 de la Ley de Enjuiciamiento Civil ${ }^{7}$ (en lo sucesivo, LEC), el cual, tan sólo permite la inadmisión de las demandas "en los casos y por las causas expresamente previstas" en la LEC. De este precepto, por tanto, no se desprende la posibilidad de rechazar in limine litis cualquier demanda, con carácter general, antes de entrar en el objeto del proceso -como se había hecho en el presente supuesto-, sino que su aplicación deberá efectuarse limitadamente.

9. En dicho sentido, y tal y como resulta de reiterada jurisprudencia del Tribunal Supremo', la redacción del artículo 403 LEC no permite rechazar de plano una demanda in limine litis, como regla general, "aunque manifiestamente se desprenda del contenido del propio escrito la inutilidad del proceso que con él se quiere iniciar [...], ya que ello afecta al derecho a la jurisdicción y corresponde hacerlo al Tribunal, mediante resolución motivada" 10 .

10. Por lo tanto, para poder considerar satisfecho el derecho fundamental a la tutela judicial efectiva reconocido en el artículo 24 de la Constitución Española, resultará conveniente proceder a "la iniciación del proceso, su desarrollo y su terminación con una sentencia sobre el fondo [...o bien, contar] con una resolución de inadmisión a trámite que sea resultado de la aplicación razonada de una causa legal y de una interpretación de la norma en el sentido más favorable para la efectividad del derecho fundamental"11.

11. Por otra parte, independientemente de que la legislación española sancione con la nulidad de pleno derecho los contratos de gestación subrogada, el artículo 46 LCJIMC no anuda a dicha nulidad la inadmisión de la demanda ${ }^{12}$, tal y como acertadamente señala el Auto de la Audiencia Provincial, sino que la solicitud de reconocimiento presentada deberá ser admitida con anterioridad para, con ello, respetar el derecho de defensa del solicitante, su derecho a ser oído en el procedimiento y ponderar el interés superior del menor frente al orden público internacional español, que no siempre deberá prevalecer ${ }^{13}$.

\footnotetext{
${ }^{6}$ Art. 46.1.a) Ley 29/2015, de 30 de julio, de cooperación jurídica internacional en materia civil.

${ }^{7}$ Ley $1 / 2000$, de 7 de enero, de Enjuiciamiento Civil.

${ }^{8}$ Art. 403.1 LEC.

${ }^{9}$ Entre otros, en el ATS, Sala de lo Civil, de 13 de octubre de 2011 [ECLI: ES:TS:2011:10367A] o en el ATS, Sala de lo Civil, de 11 de enero de 2013 [ECLI: ES:TS:2013:1091A].

${ }^{10}$ Según figura en los Razonamientos Jurídicos 2. y 3. del ATS, Sala de lo Civil, de 13 de octubre de 2011, cit., o en el Razonamiento Jurídico 2. del ATS, Sala de lo Civil, de 11 de enero de 2013, cit.

${ }^{11}$ Ibíd., en referencia a la STC 4/1988, 21 enero; STC 93/1990, 23 mayo; STC 143/1994, 9 mayo; STC 112/1997, 3 junio; o STC 125/1997, 1 julio.

${ }^{12}$ Párrafo $6^{\circ}$ Fundamento de Derecho Segundo AAP Barcelona 18 diciembre 2019.

${ }^{13}$ Como sucede, por ejemplo, "cuando el menor respecto del cual pretende inscribirse la filiación se encuentra ya en el país", supuesto en el que habrá que "tener en cuenta el interés superior del menor por encima del orden público". M. SERRA AlCEGA, "Reconocimiento de la maternidad subrogada en el Derecho internacional privado español", Revista Jurídica de la Universidad Autónoma de Madrid, nº. 32, 2015-II, p. 290.
} 
12. Aunque nuestro Tribunal Supremo, en materia de gestación subrogada, haya anclado en sentencias como la de 6 de febrero de $2014^{14}$, el orden público español "en la férrea defensa de la legalidad española y del modelo español de filiación considerado en abstracto" 15 , no podemos olvidar la postura del Tribunal Europeo de Derechos Humanos en las sentencias de los casos Mennesson vs. Francia ${ }^{16}$, Labassee vs. Francia ${ }^{17}$ o Paradiso et Campanelli vs. Italia ${ }^{18}$, en todas las cuales termina concluyendo que "la aceptación en un Estado parte de la filiación de los menores nacidos en virtud de gestación por sustitución y que consta en una certificación registral dictada en otro Estado, no vulnera, en principio, el orden público internacional del Estado de destino"19.

13. Es más, conforme afirma L. Álvarez de Toledo Quintana, las razones que adujo el Tribunal Supremo en su sentencia del año 2014 para denegar la inscripción de la filiación de los nacidos por gestación subrogada "no carecen de peso, pero tampoco son irrefutables" ${ }^{20}$, haciéndose necesario iniciar un debate sobre las nuevas necesidades de la sociedad, sobre el carácter abierto de la familia en nuestro ordenamiento o sobre "la necesidad de un status civilis único para el niño nacido en un Estado con un sistema de filiación y llevado a otro Estado con un sistema radicado en principios opuestos" ${ }^{\prime 21}$, entre otros aspectos. Esto último permitiría al menor poder "acreditar su filiación desde su nacimiento a favor de quienes han querido traerlo al mundo y garantizar la continuidad en el espacio de dicha filiación" 22 , lo que garantizaría el respeto de su interés superior y no necesariamente vulneraría nuestro orden público internacional.

14. Por todo ello, no procederá la denegación automática del reconocimiento y/o ejecución de las resoluciones extranjeras por motivos de orden público, basados en el mero hecho de que el órgano judicial extranjero hubiera aplicado un ordenamiento jurídico distinto al que hubiera resultado de las reglas del Derecho internacional privado español, ni tampoco cabrá recurrir al orden público como cláusula "abierta" que habilite, en cualquier caso, para el control de la ley aplicada a la resolución extranjera ${ }^{23}$. Así, una mera divergencia normativa per se no será suficiente para entender que existe vulneración del orden público español, ni tampoco podrá aducirse su infracción como vía indirecta para burlarla ${ }^{24}$, sino que las posibles vulneraciones del orden público internacional deberán valorarse caso por caso y no "de una forma preventiva, más allá de lo que resulta del supuesto sometido a la consideración" 25 , tal y como afirmó R. SARAZÁ JIMENA en su voto particular a la sentencia del Tribunal Supremo de 6 de febrero de 2014 citada.

\section{Parte dispositiva}

15. En definitiva, y muy acertadamente a nuestro parecer, la Audiencia Provincial de Barcelona terminó estimando el recurso de apelación interpuesto, revocando la resolución de instancia "en el senti-

${ }^{14}$ STS 835/2013, Sala $1^{\text {a }}$, Pleno, 6 febrero 2014.

${ }^{15}$ A.L. Calvo Caravaca y J. Carrascosa González, "Gestación por sustitución y derecho internacional privado. Más allá del Tribunal Supremo y del Tribunal Europeo de Derechos Humanos", Cuadernos de Derecho Transnacional, vol. 7, n. 2, octubre 2015, p. 45.

${ }^{16}$ STEDH 26 junio 2014, as. 65192/11, Mennesson vs. Francia.

${ }^{17}$ STEDH 26 junio 2014, as. 65941/11, Labassee vs. Francia.

${ }_{18}$ STEDH 27 enero 2015, Paradiso et Campanelli vs. Italia.

${ }^{19}$ A.L. Calvo Caravaca y J. Carrascosa González, "Gestación por sustitución y derecho internacional privado. Más allá del Tribunal Supremo y del Tribunal Europeo de Derechos Humanos", Cuadernos de Derecho Transnacional, vol. 7, nº 2 , octubre 2015, p. 54.

${ }^{20}$ L. Álvarez de Toledo Quintana, "El futuro de la maternidad subrogada en España: entre el fraude de ley y el correctivo de orden público internacional", Cuadernos de Derecho Transnacional, vol. 6, nº. 2, octubre 2014, p. 5.

${ }^{21}$ Ibid.

${ }^{22}$ A. Durán Ayago, "Gestación por sustitución en España: A hard case needs law, de por qué la jurisprudencia no puede resolver este problema”, Cuadernos de Derecho Transnacional, vol. 11, no. 2, octubre 2019, p. 582.

${ }^{23}$ R. Arenas García, Crisis matrimoniales internacionales. Nulidad matrimonial, separación y divorcio en el nuevo Derecho internacional privado español, Universidade de Santiago de Compostela, Santiago de Compostela, 2004, p. 365.

24 J.J. Álvarez Rubio, "Artículo 48. Prohibición de revisión del fondo", en F.P., MÉndez González y G. Palao Moreno (Dir.), Comentarios a la Ley de Cooperación Jurídica Internacional en Materia Civil, Tirant lo Blanch, Valencia, 2017, p. 563.

${ }^{25}$ Apartado Segundo del Voto particular STS 835/2013, Sala 1ª, Pleno, 6 febrero 2014 
do de dejar sin efecto la inadmisión a trámite de la demanda"26 y acordando que el Juzgado de Instancia procediera a la tramitación del procedimiento, independientemente "de la suerte que pudiera correr la petición de reconocimiento" 27 .

\section{Consideraciones finales}

16. Tras todo lo expuesto, podemos concluir que el inmovilismo a que el legislador español se aferra frente a la realidad de la gestación por sustitución, no logra disminuir la problemática ni los supuestos de inseguridad jurídica a que se enfrentan los ciudadanos españoles que se deciden a recurrir a esta figura en aquellos países en que su práctica es completamente legal.

17. Dejar en manos de los jueces la necesidad de resolver los supuestos de gestación subrogada y de aportar soluciones que garanticen los derechos de los menores nacidos a partir de estos procesos, sin dotarles de las correspondientes herramientas legales prevenidas al efecto, más allá de meros "parches" jurídicos que permiten "ir tirando", supone una gran inseguridad jurídica que precisa de una respuesta clara y sosegada acorde con esta materia tan sensible.

18. En cualquier caso, los órganos jurisdiccionales no podrán escudarse en el orden público internacional para inadmitir a trámite in limine litis cualquier demanda de solicitud de reconocimiento de una resolución extranjera que tenga por objeto un acuerdo de gestación subrogada, sino que deberán tramitar el procedimiento y dictar una sentencia sobre el fondo, o bien, inadmitir a trámite la demanda pero siempre y cuando dicha inadmisión se fundamente en la aplicación razonada de una causa legal, garantizando con ello el derecho fundamental a la tutela judicial efectiva.

19. En definitiva, independientemente de la nulidad de pleno derecho con que se hallan sancionados este tipo de acuerdos en la legislación española, ello no justifica la posibilidad de que los órganos jurisdiccionales puedan dejar de garantizar el derecho fundamental a la tutela judicial efectiva reconocido a todos los ciudadanos en la Constitución española y cuya garantía les corresponde.

\footnotetext{
${ }^{26}$ Párrafo $1^{\circ}$ Parte Dispositiva AAP Barcelona 18 diciembre 2019.

${ }^{27}$ Párrafo $6^{\circ}$ Fundamento de Derecho Segundo AAP Barcelona 18 diciembre 2019.
} 